\title{
PERANCANGAN DAN IMPLEMENTASI SISTEM PEMBAYARAN KOMITE TERINTEGRASI GUNA AKSES PENGAMBILAN KEPUTUSAN TERKAIT DENGAN TRANSPARANSI PENGGUNAAN DANA PADA SMKN 3 SORONG PROVINSI PAPUA BARAT
}

\author{
Kasmi Edy ${ }^{1}$, Markus Dwiyanto Tobi ${ }^{2}$ \\ ${ }^{1}$ Teknik Elektro, Politeknik Saint Paul Sorong \\ ${ }^{2}$ Teknik Elektro, Politeknik Saint Paul Sorong \\ 1' kasmi.edy@poltekstpaul.ac.id, ${ }^{2}$ dwivanto@ poltekstpaul.ac.id
}

\begin{abstract}
Abstrak
Sistem pembayaran keuangan dan komite sekolah pada SMK Negeri 3 Sorong saat ini masih konvensional dengan mencatat pada beberapa kartu pembayaran kemudian data pembayaran direkap secara manual pada sebuah buku catatan keuangan secara manual. Sistem ini memakan waktu proses yang cukup lama dan tingkat kesalahan yang besar, selain itu tingkat kecepatan akses data (laporannya) jika dibutuhkan sewaktu-waktu menjadi terlambat, sehingga kecepatan akses pengambilan keputusan juga menjadi terhambat. Sistem ini harus digantikan dengan menggunakan sistem informasi keuangan terintegrasi. Sistem ini dapat diakses secara publik melalui jaringan internet, sehingga diharapkan sistem ini dapat mempermudah kerja pembukuan dan pelaporan keuangan. Penelitian ini memiliki tujuan utama agar terbangunnya sistem informasi keuangan yang terintegrasi, sehingga diharapkan dengan adanya sistem ini memaksimalkan pekerjaan petugas keuangan. Hasil dari penelitian adalah produk sistem aplikasi pembayaran terintegrasi yang akan bermanfaat bagi instansi sekolah SMK Negeri 3. Penelitian ini menggunakan metode penelitian RnD, dalam mengembangkan perangkat lunak mengadopsi metode waterfall dengan tahapan perencanaan, analisis, perancangan, implementasi, pemeliharaan. Metode pengumpulan data dalam penelitian ini yaitu metode observasi dan wawancara. Aplikasi ini dikembangkan dengan menggunakan PHP dan Mysql. Sistem informasi pembayaran ini menyediakan fasilitas yang dapat digunakan oleh pengguna meliputi input data,pencarian data dan laporan pembayaran peserta didik, serta monitoring secara real time oleh wali kelas maupun stakeholder sekolah
\end{abstract}

Kata kunci : sistem terintegrasi, sistem pembayaran, pelaporan keuangan, pengambilan keputusan

\begin{abstract}
The financial payment system and school committee at SMK Negeri 3 Sorong are currently still conventional by recording on several payment cards then the payment data is recapitulated manually in a financial record book manually. This system takes a long time to process and has a large error rate. Besides, the speed of data access (reports), if needed, becomes too late, so that the speed of access to decision making is also hampered. This system should be replaced by using an integrated financial information system. This system can be accessed publicly via the internet network, so it is hoped that this system can facilitate the work of financial accounting and reporting. This research has the main objective of building an integrated financial information system, so it is hoped that this system will maximize the work of financial officers. The result of this research is an integrated payment application system product that will benefit the SMK Negeri 3 school institution. This study uses the $\mathrm{RnD}$ research method, in developing software adopting the waterfall method with the stages of planning, analysis, design, implementation, maintenance. Data collection methods in this research are observation and interview methods. This application was developed using PHP and Mysql. This payment information system provides facilities that can be used by users including data input, data search, and student payment reports, as well as real-time monitoring by homeroom teachers and school stakeholders.
\end{abstract}

Keywords: integrated systems, payment systems, financial reporting, decision making 


\section{PENDAHULUAN}

Perkembangan dalam bidang ilmu pengetahuan dan teknologi bertujuan untuk memberikan kemudahan bagi manusia dalam melaksanakan tugas dan kepentingannya. Banyak sekali bagian ilmu pengetahuan dan teknologi yang mengalami perkembangan yang begitu pesatnya, hal itu didukung oleh sumber daya alam dan sumber daya manusia yang memadai dan berkualitas. Salah satu diantaranya adalah bidang teknologi informasi dan pemrosesan data. Saat ini suatu bentuk data dibuat sesuai dengan apa yang kita inginkan, dan banyak peluang yang bisa dimanfaatkan untuk mengembangkannya.

Perkembangan dan pemanfaatan teknologi informasi terutama dalam pemanfaatan teknologi komputer juga menjadi perhatian dari kalangan pendidikan, khususnya instansi sekolah. Berbagai program sekolah bisa dikembangkan menjadi sistem yang kinerjanya menggunakan perangkat komputer, dan salah satu program tersebut adalah sistem informasi pembayaran sekolah. Saat ini komputer merupakan perangkat yang sangat dibutuhkan untuk melakukan pengolahan data dan menyajikan suatu informasi secara mudah, cepat dan akurat.[1] Dengan informasi tersebut diharapkan dapat mengatasi permasalahan dalam pengelolaan data, sehingga dapat membantu mempermudah dan memperlancar dalam pengelolaan data dan penyajian informasi. Pemanfaatan teknologi informasi oleh sebuah lembaga atau organisasi dapat mempercepat pengasksesan informasi, ketepatan waktu penyajian dan menghasilkan informasi yang akurat serta dapat memberikan pelayanan yang efektif dan efisien.[2]

Sekolah Menengah Kejuruan (SMK) Negeri 3 Sorong adalah salah satu lembaga pendidikan kejuruan yang ada di Sorong Provinsi Papua Barat. SMK ini merupakan salah satu SMK yang masuk dalam Program Revitalisasi SMK Nasional Bidang Teknologi Rekayasa. SMKN 3 Sorong yang memiliki 10 Paket keahlian dengan jumlah peserta didik diatas 1000 siswa. Dengan adanya pertambahan peserta didik setiap tahunnya menuntut lembaga atau sekolah ini untuk bisa memberikan pelayanan informasi yang baik bagi peserta didik terutama dalam hal kecepatan pelayanan akses data dan pembuatan laporan keuangan. Saat ini sistem proses pembayaran baik komite, prakerin dan lain sebagainya masih bersifat konvensional sehingga menyebabkan petugas tendik yang bertugas mengalami kesulitan dalam menangani proses pembayaran dan menyajikan laporan keuangan, serta terjadi kesalahan pencatatan dan pelaporan.

Penelitian ini bertujuan untuk membangun sistem informasi pembayaran sekolah terintegrasi pada SMK Negeri 3 Sorong yang dapat membantu kelancaran administrasi sekolah, sistem informasi pembayaran terintegrasi ini menggunakan framework PHP dan MySQL. Sistem yang akan dirancang ini berupa sebuah aplikasi mencakup pembayaran komite bulanan, pembayaran sumbangan perawatan dan perbaikan, pembayaran OSIS, pembayaran uang ujian dan pembayaran prakerin. Sistem ini akan diterapkan juga monitoring secara realtime berbasis web yang dapat diakses oleh wali kelas dan stakeholder sekolah. Laporan keuangan dapat pula tersajikan kepada orang tua sebagai bagian dari komite sekolah, sehingga sistem ini dapat mewujudkan transparansi penggunaan dana sekolah dan kemudahan dalam pengambilan keputusan terkait dengan kebijakan sekolah

\section{DASAR TEORI/MATERIAL DAN METODOLOGI/PERANCANGAN}

\subsection{Dasar Teori}

\section{Sistem Informasi}

Sistem Informasi adalah kumpulan elemen yang saling berhubungan satu sama lain yang berbentuk satu kesatuan untuk mengintegrasikan data, memproses dan menyimpan serta mendistribusikan informasi. [3]. Sistem informasi dapat didefinisikan sebagai suatu sistem yang dibuat oleh manusia yang terdiri dari beberapa komponen dalam organisasi untuk mencapai suatu tujuan yaitu menyajikan informasi.[4] 
Komponen sistem informasi terdiri dari:

1. Hardware (perangkat keras), terdiri dari komputer, printer dan jaringan.

2. Software, kumpulan perintah yang ditulis dengan aturan untuk memerintah computer melaksanakan tugas tertentu.

3. Data, merupakan komponen dasar dari informasi yang akan diproses lebih lanjut untuk menghasilkan informasi.

4. Manusia, yang terlibat dalam komponen manusia seperti operator dan pimpinan.

5. Prosedur, dokumentasi proses sistem, buku penuntun operasional (aplikasi) dan teknis. [4]

\section{Pengertian Web}

Www atau world wide web atau web saja merupakan sebuah sistem yang saling terkait dalam sebuah dokumen yang berformat hypertext yang berisi beragam informasi, baik tulisan, gambar, suara, video, dan informasi multimedia lainnya dan dapat diakses melalui sebuah perangkat yang disebut web browser. Untuk menterjemahkan dokumen dalam bentuk hypertext ke dalam bentuk dokumen yang bisa dipahami, maka web browser melalui web client akan membaca halaman web yang tersimpan di sebuah web server melalui protocol yang biasa disebut http atau Hypertext Transfer Protocol. [5]

\section{Web Server}

Web server merupakan software yang memberikan layanan data yang berfungsi yang menerima permintaan http ataupun https (hypertext transfer protocol security) dari client melalui web browser dan mengirimkan kembali hasilnya dalam bentuk halaman web yang umumnya berbentuk dokumen dalam format HTML.[5]

\section{PHP}

PHP adalah singkatan dari "PHP: Hypertext Preprocessor ", yang merupakan sebuah Bahasa scripting yang terpasang pada HyperText Markup Language (HTML). Sebagian besar sintaks mirip dengan bahasa C, Java dan Perl, ditambah beberapa fungsi PHP yang spesifik. Tujuan utama penggunaan bahasa ini adalah untuk memungkinkan perancang web menulis halaman web dinamik dengan cepat. [6]

\section{MySQL}

SQL adalah suatu bahasa komputer yang mengikuti standar American National Standard Institute (ANSI), yaitu sebuah bahasa standar yang digunakan untuk mengakses dan melakukan manipulasi sistem database [7]. Untuk melakukan administrasi dalam basis data MySQL, dapat menggunakan modul yang sudah termasuk yaitu command-line (perintah: mysql dan mysqladmin). Juga dapat di unduh dari situs MySQL yaitu sebuah modul berbasis grafik (GUI), MySQL Administrator dan MySQL Query Browser. Selain itu terdapat juga sebuah perangkat lunak gratis untuk administrasi basis data MySQL berbasis web yang sangat popular yaitu phpMyAdmin. Untuk perangkat lunak untuk administrasi basis data MySQL yang dijual secara komersial antara lain: MySQL front, Navicat dan EMS SQL Manager for MySQL.[8]

\section{Transparansi Keuangan}

Transparansi (Transparency) Transparansi dibangun atas dasar kebebasan arus informasi. Proses lembaga dan informasi secara langsung dapat diterima oleh meraka yang membutuhkan. Informasi harus dapat dipahami dan dapat dimengerti. Menurut Sedarmayanti [2] transparansi adalah tata kelola pemerintahan yang baik akan bersifat transparan terhadap rakyatnya, baik di tingkat pusat maupun daerah. Transparansi adalah bahwa individu, kelompok, atau organisasi dalam hubungan 
akuntabilitas diarahkan tanpa adanya kebohongan atau motivasi yang tersembunyi, dan bahwa seluruh informasi kinerja lengkap dan tidak memiliki tujuan menghilangkan data yang berhubungan dengan masalah tertentu. Transparansi adalah prinsip yang menjamin akses atau kebebasan bagi setiap orang untuk memperoleh informasi tentang penyelenggaraan pemerintah, yakni tentang kebijakan, proses pembuatan dan pelaksanaan serta hasil-hasil yang dicapai. Transparansi bermakna tersedianya informasi yang cukup, akurat dan tepat waktu tentang kebijakan publik dan proses pembentukannya. Dengan ketersediaan informasi seperti itu, masyarakat dapat ikut sekaligus mengawasi sehingga kebijakan publik yang muncul bisa memberikan hasil yang optimal bagi masyarakat, serta mencegah terjadinya kecurangan dan manipulasi yang hanya menguntungkan salah satu kelompok masyarakat saja. Keterbukaan dan transparansi juga dalam arti masyarakat atau sesama aparatur pemerintah dapat mengetahui atau dilibatkan dalam perumusan perencanaan, pelaksanaan, dan pengawasan dengan pengendalian pelaksanaan kebijaksanaan publik yang terkait dengan kegiatan di Pemerintah. [9]

\subsection{Metode Penelitian}

Penelitian ini bertujuan untuk mengembangkan produk atau system informasi pembayaran keuangan terintegrasi untuk menunjang akses kebijakan sekolah dan transparansi penggunaan dana keuangan yang diterima oleh sekolah. Penelitan ini termasuk dalam penelitian Research and Development (R \& D) untuk menghasilkan produk tertentu dan mengkaji keefektifan produk yang dihasilkan. Menurut Borg \& Gall [10] dikatakan Educational Research and development (R\&D) adalah suatu proses untuk mengembangkan dan memvalidasi hasil produk. Kerangka metode atau alur penelitian yang diusulkan adalah sebagai berikut:

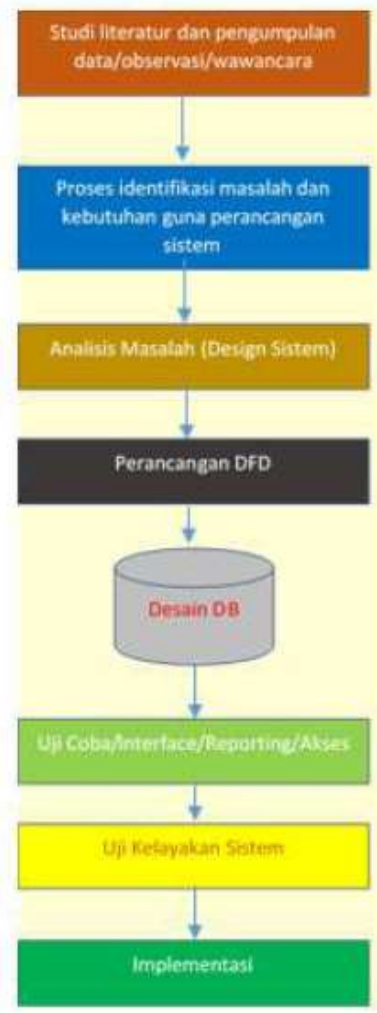

Gambar 1. Metode/Alur Penelitian 
Hasil dari penelitian berupa sistem perngkat lunak sehingga dalam penelitian ini perlu dilakukan penyelarasan tahapan. Metode penyelarasan menggunakan metode Waterfall dengan tahapan berupa, perencanaan, analisis, perancangan, implementasi, dan pemeliharaan.[10]

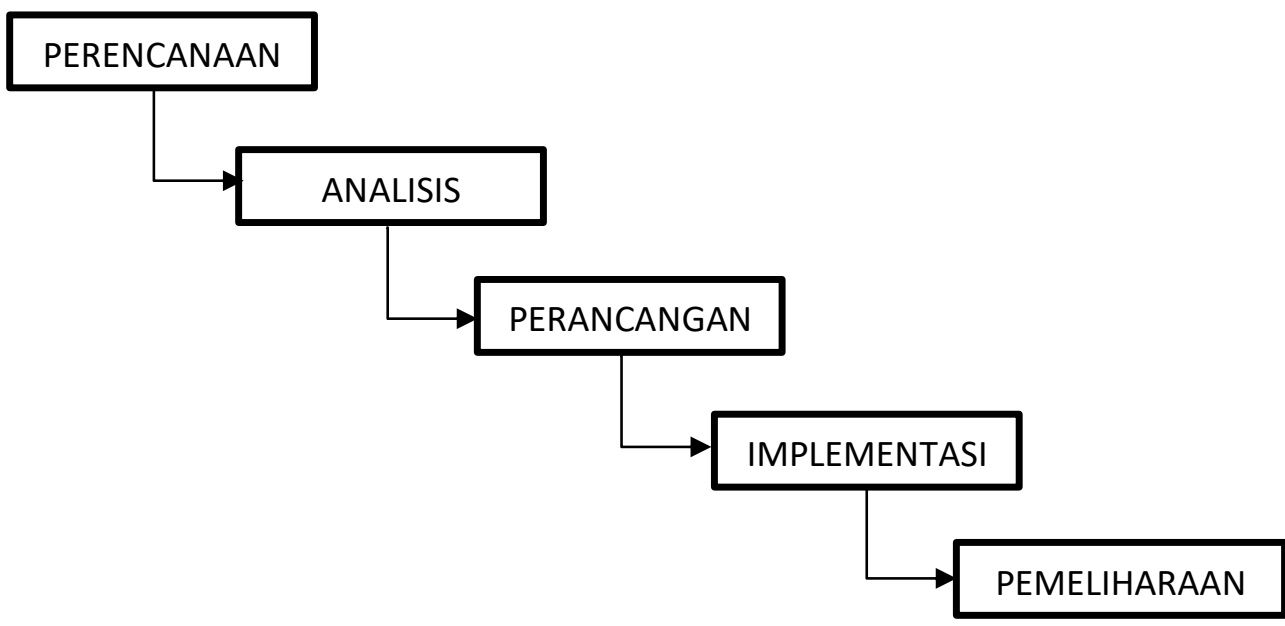

Gambar 2. Metode Waterfall

Aplikasi yang diimpelentasikan menggunakan jaringan internet dan jaringan LAN sekolah SMK Negeri 3 Sorong, dengan sistem kerja membutuhkan sebuah server (yang harus diinsal aplikasi XAMPP dan dipasang aplikasi SIP ke dalam folder XAMPP/htdocs) kemudian di share melalui browser (chrome, mozila, dll) mengunakan URL localhost atau IP Address publik dengan menggunakan sebuah sub domain. Aplikasi ini memuat data siswa, jenis pembayaran, data walikelas dan petugas yang akan melaksanakan proses transaksi atau administrasi pembayaran, sistem ini juga dintegrasikan dengan website milik sekolah.

Penelitian dilakukan sejak bulan Januari-Maret tahun 2020, telah beberapa kali melakukan proses pengambilan data di SMK Negeri 3 Sorong, sekaligus melakukan pengumpulan data permasalahan yang ada terkait dengan proses administrasi pembayaran komite. Proses pengujian dan implementasi uji coba aplikasi ini diantaranya adalah proses import data siswa dan walikelas, jurusan dan jumlah rombel yang ada di sekolah.

\section{PEMBAHASAN}

\subsection{Hasil Penelitian}

SMK Negeri 3 Kota Sorong sebagai salah satu lembaga penyelenggara pendidikan merasa berkewajiban untuk berperan serta membekali tamatannya dengan kecakapan hidup (life skill) secara integratif, yang memadukan potensi generik dan spesifik, guna memecahkan dan mengatasi problema hidup. Kecakapan hidup yang mestinya dimiliki oleh setiap tamatan yang akan terjun ke masyarakat ter-sebut antara lain, Kecakapan mengenal diri (personal skil ), kecakapan berpikir rasional (thinking skill), kecakapan social (social skill), kecakapan akademik (academic skill) dan kecakapan kejuruan (vocational skill).

SMK Negeri 3 Sorong, sebagai salah satu sekolah jenjang SMK tertua di Provinsi Papua Barat yang didirikan sejak tahun 1986 (SK Pendirian 0890/01/19) telah memiliki 10 kompetensi keahlian, yakni sebagai berikut: 
JEC Vol. 6 No. 2

Jurnal Electro Luceat [November] [2020]

Tabel 1 Status Akreditasi Kompetensi Keahlian di SMK N 3 Sorong

\begin{tabular}{|c|l|c|}
\hline NO & \multicolumn{1}{|c|}{ Kompetensi Keahlian } & Status Akreditasi \\
\hline 1. & Teknik Pemesinan & A \\
\hline 2. & Teknik Pengelasan & $\mathrm{A}$ \\
\hline 3. & Teknik Elektronika Audio Video & $\mathrm{A}$ \\
\hline 4. & Teknik Elektronika Industri & $\mathrm{A}$ \\
\hline 5. & Teknik Kendaraan Ringan Otomotif & $\mathrm{A}$ \\
\hline 6. & Teknik Alat Berat & $\mathrm{A}$ \\
\hline 7. & Teknik Instalasi Tenaga Listrik & $\mathrm{A}$ \\
\hline 8. & Desain dan Pemodelan Informasi Bangunan & $\mathrm{A}$ \\
\hline 9. & Bisnis Konstruksi dan Properti & $\mathrm{A}$ \\
\hline 10. & Teknik Komputer dan Jaringan & $\mathrm{A}$ \\
\hline
\end{tabular}

Penerimaan siswa baru selama 3 (tiga) tahun terakhir terus mengalami animo peningkatan, berikut data penerimaan siswa baru dalam 3 tahun terakhir:

Tabel 2 Penerimaan Siswa Baru Selama 3 Tahun Terakhir

\begin{tabular}{|c|c|c|c|c|c|c|c|}
\hline \multirow[b]{2}{*}{ NO } & \multirow[b]{2}{*}{ Program Keahlian } & \multicolumn{2}{|c|}{ Tahun 2018} & \multicolumn{2}{|c|}{ Tahun 2019} & \multicolumn{2}{|c|}{ Tahun 2020} \\
\hline & & \begin{tabular}{|c|} 
Jumlah Siswa \\
Pendaftar \\
\end{tabular} & $\begin{array}{c}\text { Jumlah Siswa } \\
\text { diterima }\end{array}$ & \begin{tabular}{|c|} 
Jumlah Siswa \\
Pendaftar \\
\end{tabular} & \begin{tabular}{|c|}
$\begin{array}{c}\text { Jumlah Siswa } \\
\text { diterima }\end{array}$ \\
\end{tabular} & \begin{tabular}{|c|}
$\begin{array}{c}\text { Jumlah Siswa } \\
\text { Pendaftar }\end{array}$ \\
\end{tabular} & $\begin{array}{c}\text { Jumlah Siswa } \\
\text { diterima }\end{array}$ \\
\hline 1. & Teknik Mesin & 102 & 99 & 102 & 98 & 96 & 73 \\
\hline 3. & Teknik Otomotif & 140 & 121 & 120 & 112 & 172 & 144 \\
\hline 4. & Teknik Ketenagalistrikan & 80 & 72 & 86 & 72 & 97 & 73 \\
\hline & Jumlah Siswa & 557 & 482 & 551 & 498 & 735 & 549 \\
\hline
\end{tabular}

Data Siswa Tahun Pelajaran 2020/2021 dapat digambarkan dalam tabel berikut:

Tabel 3 Data Siswa Tahun Pelajaran 2020/2021

\begin{tabular}{|c|l|c|}
\hline NO & \multicolumn{1}{|c|}{ Kompetensi Keahlian } & Jumlah Siswa \\
\hline 1. & Teknik Pemesinan & 137 \\
\hline 2. & Teknik Pengelasan & 98 \\
\hline 3. & Teknik Elektronika Audio Video & 54 \\
\hline 4. & Teknik Elektronika Industri & 46 \\
\hline 5. & Teknik Kendaraan Ringan Otomotif & 294 \\
\hline 6. & Teknik Alat Berat & 84 \\
\hline 7. & Teknik Instalasi Tenaga Listrik & 200 \\
\hline 8. & Desain dan Pemodelan Informasi Bangunan & 172 \\
\hline 9. & Bisnis Konstruksi dan Properti & 98 \\
\hline 10. & Teknik Komputer dan Jaringan & 234 \\
\hline & Jumlah Siswa Keseluruhan & $\mathbf{1 4 1 7}$ \\
\hline
\end{tabular}

Sedangkan jumlah peserta didik berdasarkan jenis kelamin pada Tahun Pelajaran 2020/2021 dapat digambarkan dalam diagram dibawah ini: 
JEC Vol. 6 No. 2

Jurnal Electro Luceat [November $][2020]$

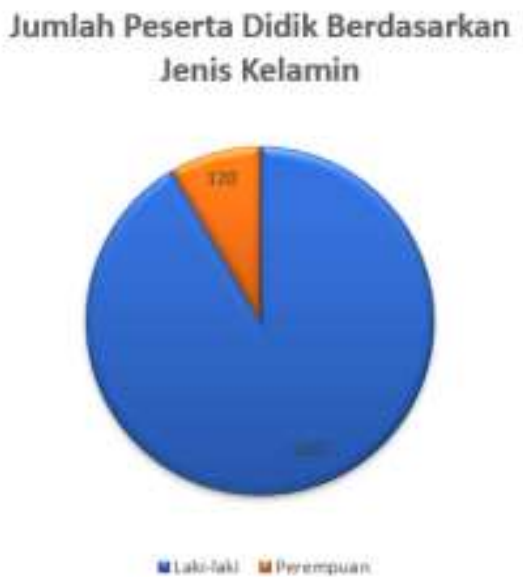

Gambar 3. Diagram Jumlah Peserta Didik Berdasarkan Jenis Kelamin Tahun Pelajaran 2020/2021

Terkait dengan jumlah data Guru Produktif, tidak dapat dipungkiri saat ini SMK Negeri 3 Sorong memiliki jumlah Guru Produktif yang sangat terbatas, oleh karena beberapa guru produktif telah memasuki usia pensiun dan tidak adanya penerimaan calon guru produktif SMK oleh Pemerintah. Keadaan guru produktif di SMKN 3 Sorong Tahun Pelajaran 2020/2021 dapat digambarkan dalan tabel dibawah ini:

Tabel 4. Jumlah Guru Produktif di SMKN 3 Sorong

\begin{tabular}{|c|l|c|c|}
\hline NO & \multicolumn{1}{|c|}{ Kompetensi Keahlian } & PNS & Honorer \\
\hline 1. & Teknik Pemesinan & 2 & 1 \\
\hline 2. & Teknik Pengelasan & 1 & \\
\hline 3. & Teknik Elektronika Audio Video & 2 & \\
\hline 4. & Teknik Elektronika Industri & 6 & \\
\hline 5. & Teknik Kendaraan Ringan Otomotif & 2 & 1 \\
\hline 6. & Teknik Alat Berat & 3 & 2 \\
\hline 7. & Teknik Instalasi Tenaga Listrik & 3 & 1 \\
\hline 8. & Desain dan Pemodelan Informasi Bangunan & 2 & 6 \\
\hline 9. & Bisnis Konstruksi dan Properti Jumlah & 23 & 11 \\
\hline 10. & Teknik Komputer dan Jaringan Jumlah Keseluruhan & \multicolumn{2}{|c|}{$\mathbf{3 4}$} \\
\hline & \multicolumn{2}{r}{} \\
\hline
\end{tabular}

\subsection{Perancangan Database}

Setelah beberapa data yang dikumpulkan dan melakukan wawancara terkait dengan permasalahan yang ada. Peneliti melakukan analisis dan perancangan database guna menghasilkan sebuah aplikasi bantu dalam menanganin permasalahan pembayaran komite di SMKN 3 Sorong. Rancangan database dari aplikasi dapat digambarkan sebagai berikut: 


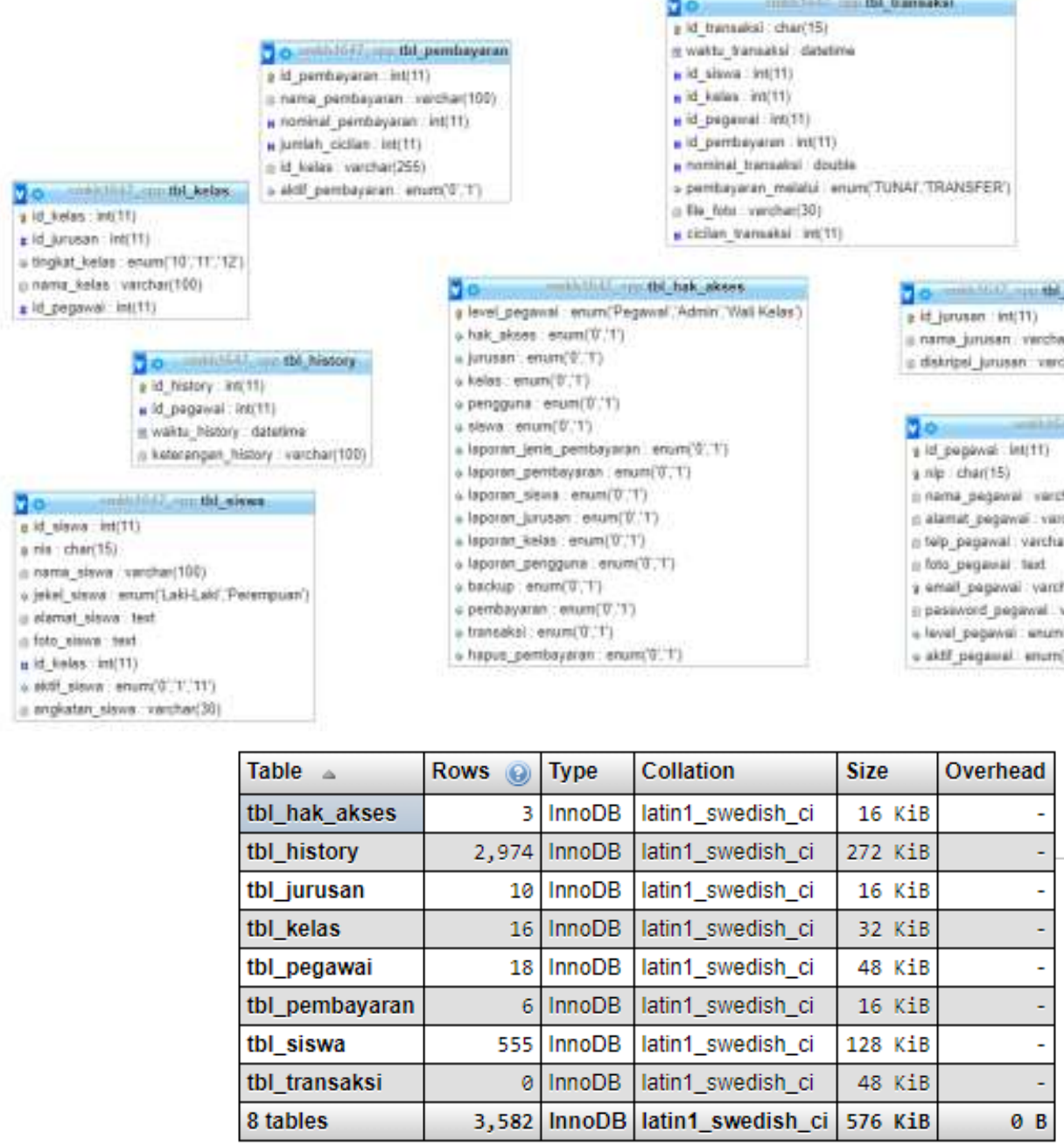

Gambar 4. Hasil Analisis Perancangan Database

\subsection{Pengembangan Aplikasi Pembayaran}

Aplikasi pembayaran terintegrasi ini dirancang menggunakan bahasa pemrograman PHP dan database MySql yang berjalan di engine XAMPP sebagai webserver aplikasi. Berikut tampilan antarmuka aplikasi yang dirancang:

\section{Tampilan Awal}

Berikut merupakan gambar tampilan awal aplikasi:

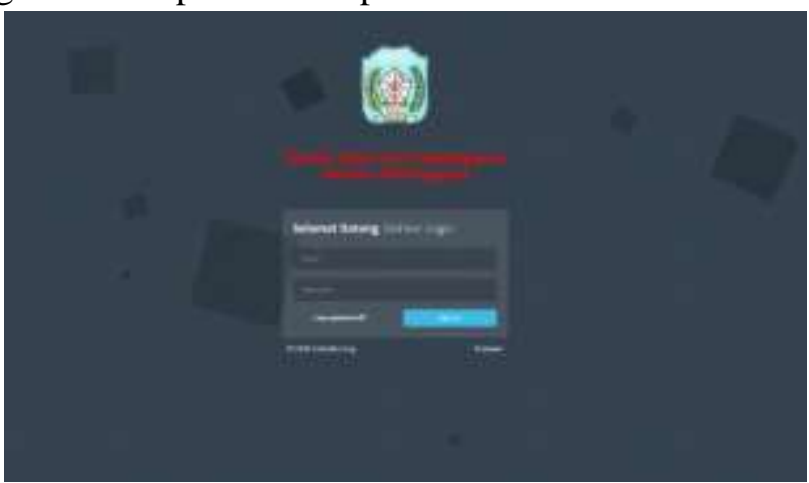

Gambar 5. Tampilan Awal Aplikasi 
2. Menu Admin

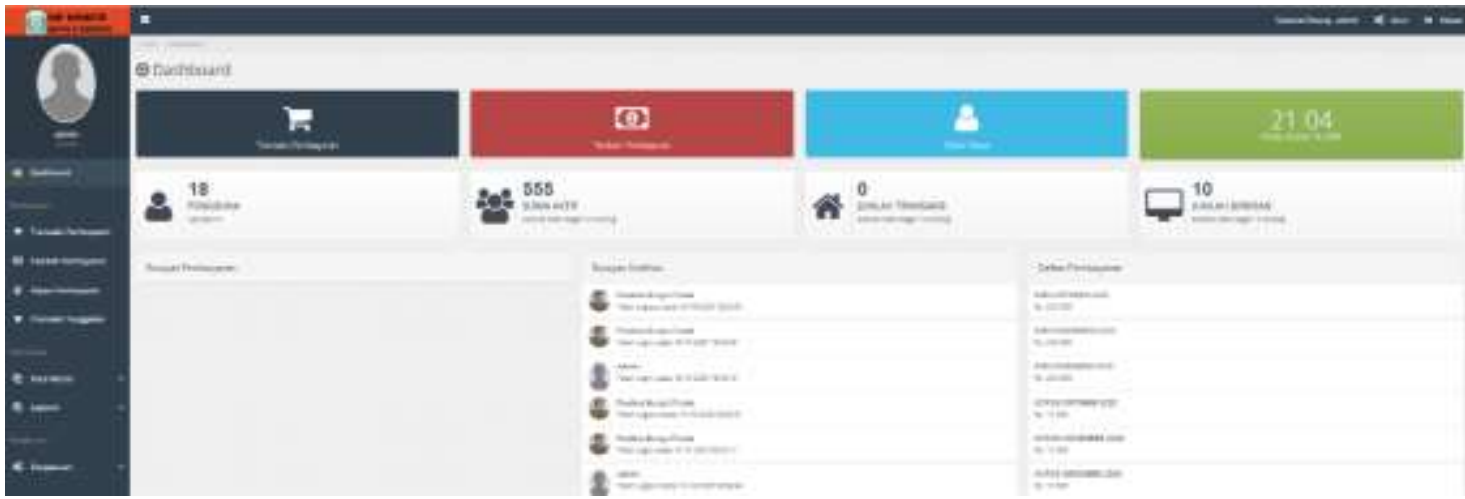

Gambar 6. Menu Admin

Menu admin digunakan untuk mengadministrasi sistem aplikasi, diantaranya memasukkan data siswa, pegawai, kelas, rombel, dan data walikelas, selain itu menu admin ini juga digunakan untuk melakukan administrasi user.

\section{Menu Pegawai (Petugas Transaksi)}

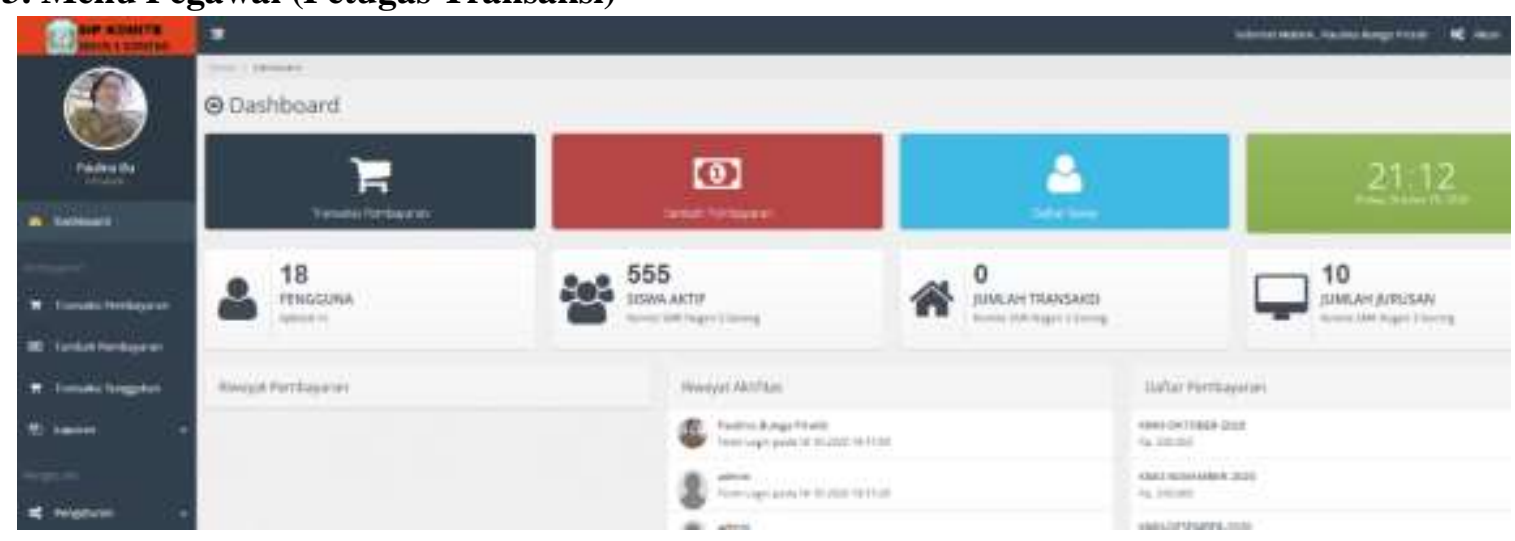

Gambar 7. Menu Pegawai (Petugas Transaksi)

Menu petugas ini digunakan untuk proses transaksi dan administrasi pembayaran, melakukan penagihan, transaksi pelunasan dan pembuatan laporan keuangan.

\section{Menu Walikelas}

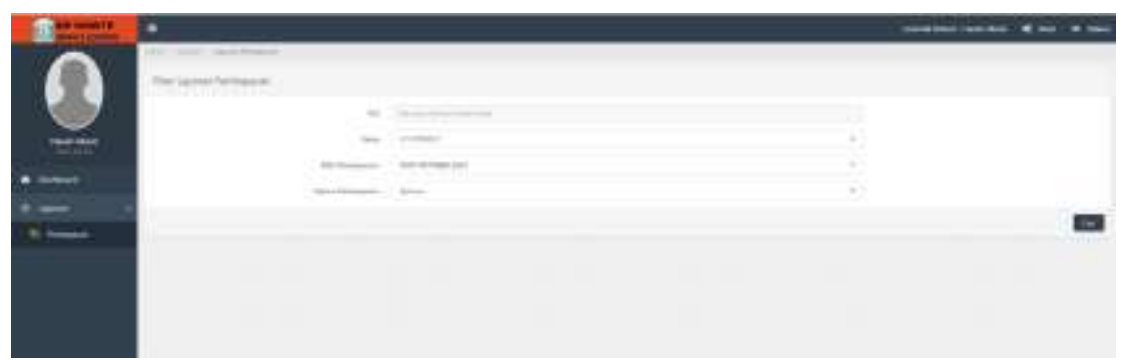

Gambar 8. Menu Wali Kelas

Menu walikelas ini digunakan sebagai sarana pengecekan walikelas dan monitoring pembayaran peserta didik dalam kelasnya. Menu walikelas ini juga dapat digunakan walikelas sebagai sarana informasi transparansi kepada orang tua peserta didik. 


\section{Laman Reporting}

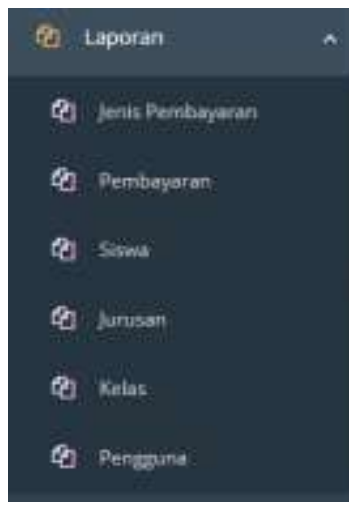

Gambar 9. Laman Reporting

Laman reporting atau laporan ini terdiri atas beberapa sub menu, yakni:

a. Laporan Jenis Pembayaran

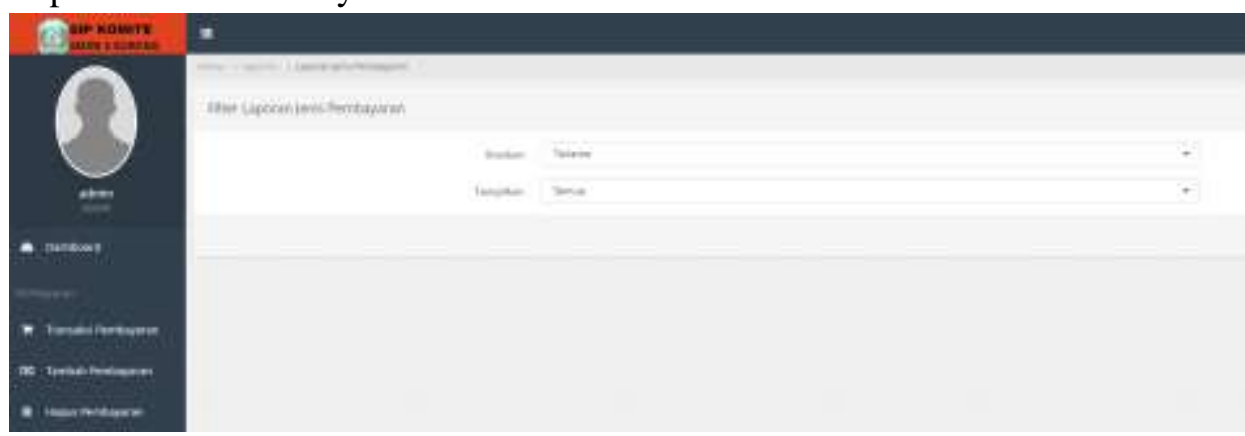

b. Laporan Pembayaran Siswa

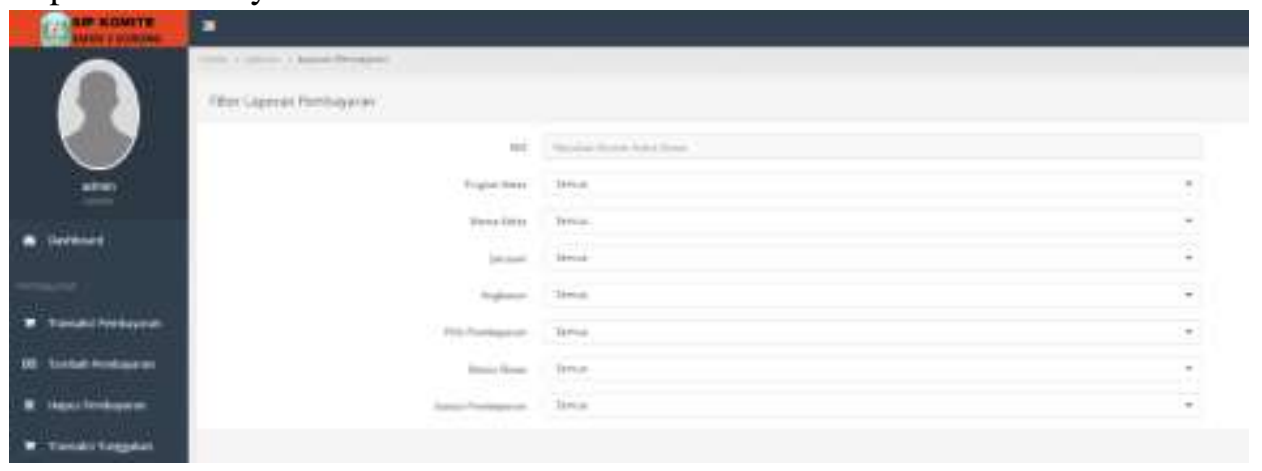

c. Laporan Siswa/Rombel Per siswa

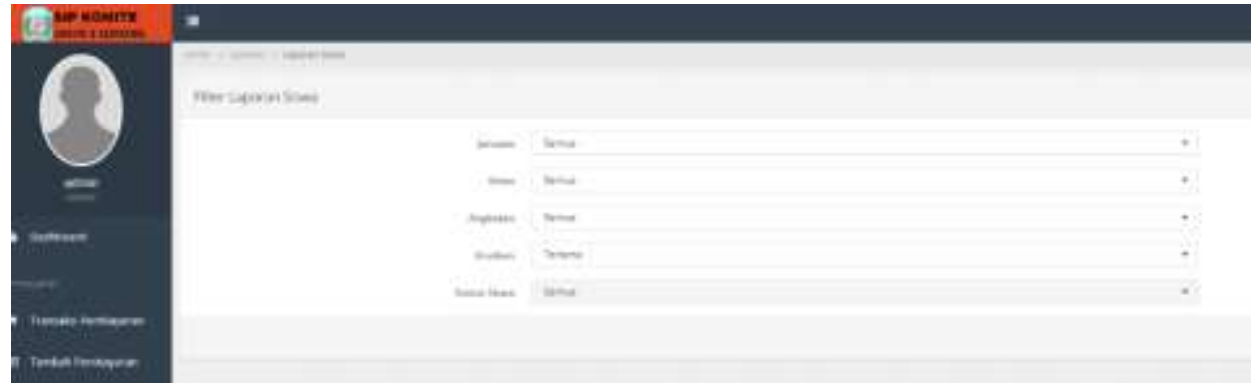


d. Laporan Rincian Jurusan

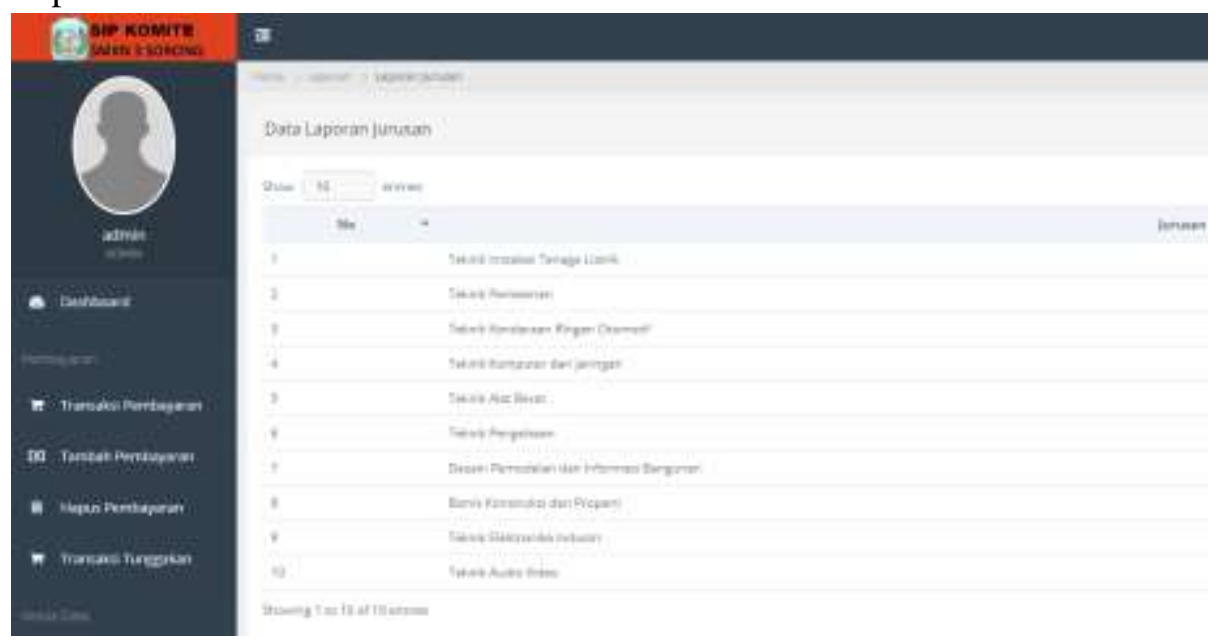

e. Laporan Kelas/Rombel

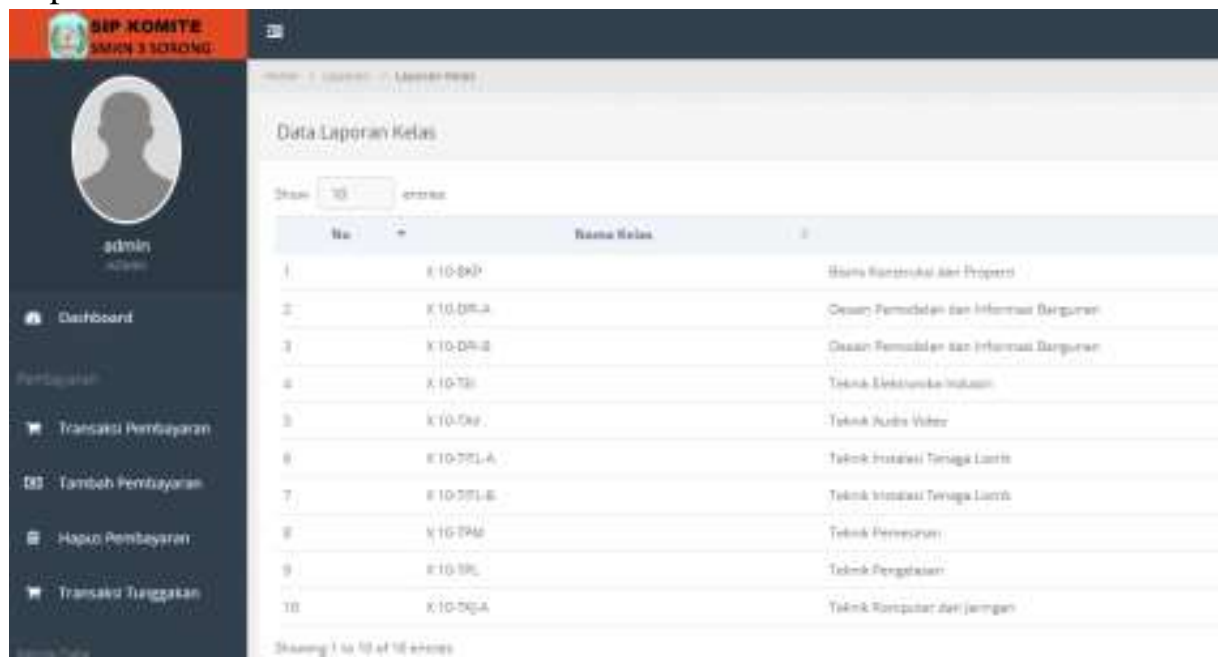

f. Laporan Rekap Pengguna/Walikelas/Petugas

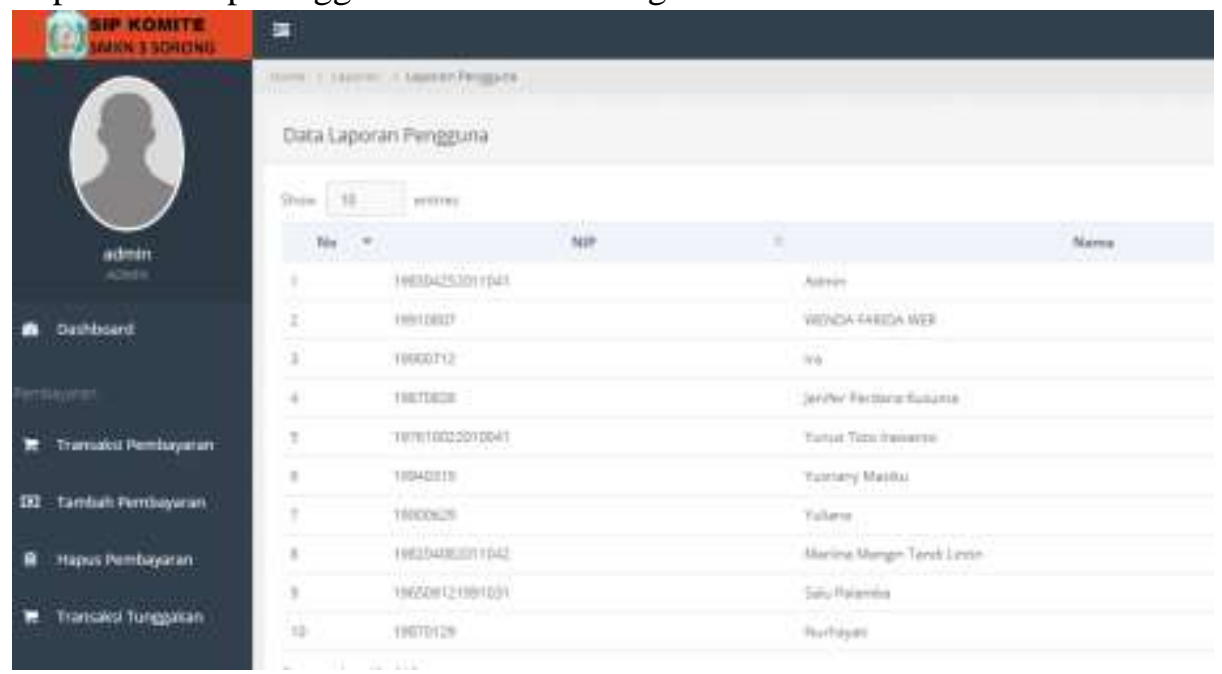


Peneliti pada bulan Juli-Agustus tahun 2020, telah melaksanakan 2 (dua) kali tatap muka daring dengan para guru untuk mendemokan hasil rancangan dan menerima masukan dan saran perbaikan dan pengembangan kedepan.

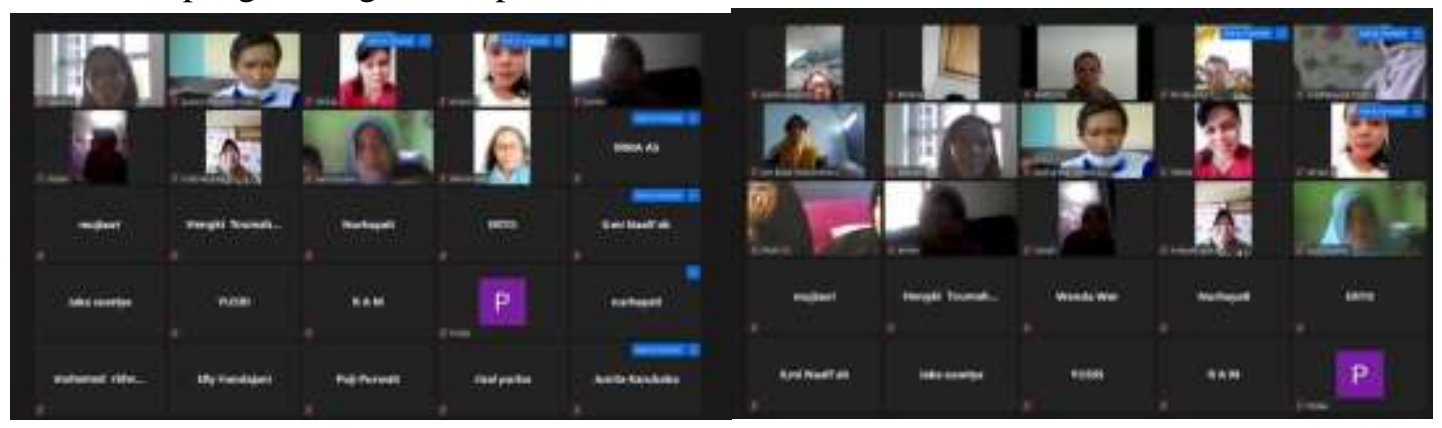

Gambar 9. Demo Hasil Rancangan

\section{KESIMPULAN}

Berdasarkan hasil penelitian dan perancangan system terintegrasi yang telah dilakukan maka dapat diambil kesimpulan sebagai berikut:

1. Pelaksanaan pembayaran uang komite peserta didik SMKN 3 Sorong secara terintegrasi dapat memberikan transparansi bagi seluruh warga sekolah dan komite sekolah.

2. Aplikasi system informasi terintegrasi ini dapat juga memberikan laporan secara cepat bagi walikelas dalam mengakses dan memberikan informasi kepada siswa dan orang tua.

3. Aplikasi system informasi terintegrasi ini dapat diakses secara public atau online sehingga dapat diakses oleh warga sekolah darimana saja.

\section{DAFTAR PUSTAKA}

[1] Yuanita, Sukadi. 2012. Sistem Informasi Administrasi Pembayaran Iuran Bulanan (SPP) dan Dana Sumbangan Pendidikan (DSP) Siswa Taman Kanak-Kanak Negeri Pembina Kecamatan Pringkuku. Jurnal Speed 13 Vol 9 No 2. Universitas Surakarta.

[2] Ali Syahbana, Bambang Eka Purnama, Sukadi. 2012. Pembangunan Sistem Informasi Administrasi Pembayaran Siswa Madrasah Aliyah Ma'arif Pacitan. Jurnal Speed 13 Vol 9 No 2. Universitas Surakarta.

[3] Budi Sutedjo Dharma Oetomo,S.Kom.,MM,Perencanaan dan Pembangunan Sistem Informasi

[4] Park, J.Z. and Taylor, C.R., 2007. Information resources of elite ministry professionals. Review of religious research, pp.428-436.

[5] Erinawati, H.D., 2013. Pembangunan Sistem Informasi Pembayaran Sekolah Pada Sekolah Menegah Atas (SMA) Negeri 1 Rembang Berbasis Web. Speed-Sentra Penelitian Engineering dan Edukasi, 4(4).

[6] Ullman, L., 2011. PHP and MySQL for Dynamic Web Sites: Visual QuickPro Guide. Peachpit Press.

[7] Yakub. 2012. Pengantar Sistem Informasi. Yogyakarta : Graha Ilmu.

[8] Kadir, Abdul. 1999. Konsep dan Tuntutan Praktis Basis Data. Yogyakarta. Andi.

[9] Sari, D., 2012. Pengaruh pengendalian internal terhadap transparansi laporan keuangan Pemerintah Daerah.

[10] Saptono, Marcell, and Herry Widjasena. 2019. "PERANCANGAN DAN IMPLEMENTASI APLIKASI UJIAN SEKOLAH BERBASIS KOMPUTER ATAU COMPUTER BASED TEST (CBT) DI SMK NEGERI 1 KABUPATEN SORONG”. Electro Luceat 5 (2), 5-13. https://doi.org/10.32531/jelekn.v5i2.148. 